\title{
Medicinal Plants, A promising Source of Natural Fungicides against Magnaporthe oryzae Triticum, Causal Agent of Wheat Blast
}

\author{
Abul Hasnat Md. Shamim \\ School of Agriculture and Rural Development, Bangladesh Open University, Gazipur, Bangladesh \\ Email: shamimsard@gmail.com
}

How to cite this paper: Shamim, A.H.Md. (2021) Medicinal Plants, A promising Source of Natural Fungicides against Magnaporthe oryzae Triticum, Causal Agent of Wheat Blast. American Journal of Plant Sciences, 12, 748-758.

https://doi.org/10.4236/ajps.2021.125051

Received: April 10, 2021

Accepted: May 23, 2021

Published: May 26, 2021

Copyright $\odot 2021$ by author(s) and Scientific Research Publishing Inc. This work is licensed under the Creative Commons Attribution International License (CC BY 4.0).

http://creativecommons.org/licenses/by/4.0/

\begin{abstract}
Wheat blast, caused by a fungal pathogen, Magnaporthe oryzae Tritichum (MoT) pathotype (wheat isolates), was first reported in Bangladesh among Asian countries in 2016. It is a serious disease of wheat causing yield failures and significant economic losses during epidemic years. Extensive use of persistent synthetic pesticides to control notorious wheat blast imposes enormous threat to human health and environment. In addition, the increasing demand for organic food has stimulated people to look for alternative methods. Nowadays, the need for synthetic chemical-free agricultural practices is gaining importance due to effective in managing crop pests, inexpensive, biodegradable, easily available and have low toxicity to non-target organisms. In order to identify active plants, 12 kinds of methanol extracts obtained from 12 medicinal plants were conducted in vitro to test the effect against Magnaporthe oryzae Triticum (MoT) pathotype. The remarkable inhibitory activity $\{(29.6 \pm 01.5) \mathrm{mm},(25.1 \pm 01.0) \mathrm{mm}$ and $(20.0 \pm 02.0) \mathrm{mm}$ zone of inhibition)\} exhibited by the extracts ( $5 \mathrm{mg} /$ disk) obtained from Artemisia indica (Nagdona), Persicaria orientalis (Bishkatali) and Clerodendrum indicum (Bamonhati), respectively. Other medicinal plant extracts did not show any significant or no activity at all. Therefore, the three plant extracts might be a promising source for developing natural fungicides against wheat blast.
\end{abstract}

\section{Keywords}

Medicinal Plants, Extracts, Activity, Fungicides, Zone of Inhibition, Wheat Blast

\section{Introduction}

Agriculture in the 21st century faces multiple challenges: emerging resistant 
pests, drought, climate change, etc. In addition, United Nations had been reported that the world's population is expected to increase by 2 billion in the next 30 years, from presently 7.7 billion to 9.7 billion in 2050. To feed this huge growing population, more activities have been directed toward the sustainable agriculture practices. Due to increased demand for foods to feed the ever-growing population led to development and adoption of synthetic chemicals as a quick and effective strategy of managing crop pests and diseases [1].

Some scientists claimed that the status of food security and food safety are alarming in Bangladesh due to crop losses by pests, emerging newly and resistant crop pathogens, and use of excessive synthetic pesticides [2] [3] [4].

Increasing rate of emerging fungal diseases in crop plants is a serious threat to food and nutritional security of increasing population in the world [5] [6]. One of the striking examples is the new emergence and re-emergence of blast disease which is caused by distinct pathotypes of a filamentous fungus Magnaporthe oryzae [7] [8]. Presently, wheat blast disease has emerged as a threat for global wheat production [9].

Bangladesh is an agro-based country. Livelihood of $80 \%$ population of Bangladesh is directly or indirectly dependent on agriculture. In last couple of decades, Bangladesh has progressed remarkably in food production and developing high yield seeds of vegetables and crops which leading Bangladesh to be self-sufficient of food. On the contrary, Bangladesh has not yet developed environmental friendly chemicals to control diseases of vegetables and crops caused by fungi. As a result, farmers are forced to heavily rely on heavy metal containing synthetic fungicides to control diseases of vegetables and crops. These heavy metals (such as copper, cadmium, tin, etc) containing fungicides are imposing enormous threat to human health (cancer, neurological defects, asthma, allergies, birth defects, etc) and soil fertility. Excessive use of non-biodegradable pesticides may lead to the destruction of biodiversity. Many birds, aquatic and soil organisms and animals are under threat of harmful, synthetic and persistent (non-biodegradable) pesticides for their survival which challenges food security [10].

Wheat is the second staple food in Bangladesh after rice. Lately, wheat blast, a new devastating fungal disease caused by Magnaporthe oryzae Tritichum (MoT) has been observed in eight southwestern districts, viz., Meherpur, Chuadanga and so on. In February 2016, Bangladesh was reported as the first Asian country havingan outbreak of worrisome wheat blast disease caused by a South American lineage of a hemibiotrophic filamentous fungus MoT pathotype [1] [11] [12].

Wheat blast disease is wide spread in Bangladesh at this moment. The epidemic spread to an estimated 15,000 hectares, about $16 \%$ of the cultivated wheat area in Bangladesh, with yield losses reaching up to $100 \%$ which threatening food security. The existing synthetic fungicides are inactive against notorious wheat blast fungus to be physiologically different from true fungi. Moreover, the 
currently available synthetic fungicides are persistent chemicals, whose toxicity represents enormous threats to the ecosystem, human health, and the environment as well. Therefore, it has become inevitable to search for safer and environmentally friendly fungicides from natural sources including medicinal plants.

Most of the agricultural research conducted in the $20^{\text {th }}$ century focused on increasing crop productivity but not developing environmental friendly natural pesticides for sustainable food production. The synthetic pesticides were immediately accepted after development due to their effectiveness and efficacy in managing serious crop diseases [13]. Consequently, the use of natural products of plant origin slowly faded until recently when use of synthetic pesticides started threatening human health and environmental safety [14]. Currently, organic foods produced by using plant-based pesticides are gaining popularity due to detection of hazardous residues of synthetic pesticides in foods and increased awareness among consumer on food safety [15] [16].

Natural products which are safe for the environment and have low toxicity to living organisms are gaining interest as important sources for the development of fungicides, and these may serve as effective substitutes for synthetic fungicides [17] [18]. Therefore, to increase food security and food safety and sustainable food production and to control wheat blast disease, we need urgently natural, environment friendly pesticides. The main focus of this study was to evaluate in vitro efficacy of 12 medicinal plant extracts (methanol extracts) against wheat blast caused by notorious fungal pathogen, Magnaporthe oryzae Triticum (MoT) pathotype.

\section{Materials and Methods}

\subsection{General Experimental Procedures}

Methanol (Scharlau, Spain), potato dextrose agar (PDA) (Scharlau, Spain), sterile filter paper disk (BioMaxima S.A., Poland), filter paper (Whatman Int. Ltd. Maid Stone, England), heavy duty blender (Havells, India), colorimeter (Model-S 9121, Systonic, India), vortex machine (VM-10, witeg, Germany) and iprodione (Auto Crop Care Ltd, Dhaka, Bangladesh) were bought from local suppliers. Sterilization, aseptic works and solvent evaporation were done using vertical autoclave machine (Model: LVA-202, Labocon, UK), horizontal laminar airflow cabinet (Model: LLFH-204, Labocon, UK) and rotary evaporator (Model: HS-2005S-N, Hahnshin S\&T Co., Ltd. Korea). All used solvents and reagents were analytical and reagent grades, respectively.

\subsection{Collection and Storage of Medicinal Plants}

Healthy stems and leaves of 12 medicinal plants (Table 1) were collected through an expedition in 2019 from Modhupur under Tangali districts. These plants were collected in plastic bags. The plant parts (leaves and stems) were thoroughly washed under running tap water, chopped into small pieces and dried under shade for 2 - 3 weeks in the food and nutrition lab, Bangladesh 
Open University, Gazipur. After drying, the plant materials were grinded into fine powdered form by using a blender, kept in plastic bags and stored in refrigerator.

\subsection{Extraction of Medicinal Plants}

$5 \mathrm{~g}$ fine powder of each plants were soaked in $100 \mathrm{~mL}$ methanol for overnight and filtered through Whatman filter paper No. 1 to obtain a clear filtrate. The filtrates were evaporated and dried at $40^{\circ} \mathrm{C}$ under reduced pressure using rotatory vacuum evaporator. The extract yields were weighted and yield percentages were calculated using the following formula: Extract yield $(\mathrm{g} / 100 \mathrm{~g})=\left(W_{1} \times\right.$ 100)/ $W_{2}$ where $W_{1}$ is the weight of the extract residue obtained after solvent removal and $W_{2}$ is the powder weight of plants. These extracts were subjected to activity screening against $M o T$ pathotype.

\subsection{Collection of Test Pathogens}

The test pathogen, Magnaporthe oryzae Triticum (MoT) pathotype, was collected from Bangladesh Wheat and Maize Research Institute (BWMRI), Nashipur, Dinajpur, Bangladesh. This test pathogen was isolated from infected wheat. Other test pathogen was collected from Bangladesh Rice Research Institute (BRRI), Gazipur, Bangladesh and identified as Penicillium sp. based on $16 \mathrm{~S}$ rDNA sequence analysis which had similarity $99.82 \%$ for Penicillium citrinum and $99.81 \%$ for Penicillium brevicompactum.

\subsection{Seed Culture of the Test Pathogen}

To study activity of medicinal plants (Table 1), first the test pathogen (MoT pathotype) was streaked on the sterilized potato dextrose agar (PDA) medium

Table 1. List of medicinal plants (vernacular, common, scientific and family names) used for activity screening against Magnaporthe Oryzae Triticum (MoT) pathotype.

\begin{tabular}{ccccc}
\hline SL & Vernacular Name & Common Name & Scientific Name & Family Name \\
\hline 1 & Sorpogandha & Snake root & Rauvolfia serpentia & Apocynaceae \\
2 & Joyunti & Common sesban & Sesbania sesban & Fabaceae \\
3 & Polash & Bastard teak & Butea monosperma & Fabaceae \\
4 & Sugandhibala & Pandan & Pandanus amaryllifolius & Pandanaceae \\
5 & Vhuikumra & Giant potato & Ipomoea mauritiana & Convolvulaceae \\
6 & Biskatali & Oriental pepper & Persicaria orientalis & Polygonaceae \\
7 & Joipal & Purging nut & Croton tiglium & Euphorbiaceae \\
8 & Bamonhati & Sky rocket & Clerodendrum indicum & Lamiaceae \\
9 & Punarnava & Pig weed & Boerhaavia repens & Nyctaginaceae \\
10 & Aunantamul & Indian sarsaparilla & Hemidesmus indicus & Asclepiadaceae \\
11 & Nagdona & Asian mugwort & Artemisia indica & Asteraceae \\
12 & Currypata & Bead-tree & Melia sempervirens & Meliaceae \\
\hline
\end{tabular}


(prepared according to the manufacturer's guideline) (3.9\% w/v) from stock culture and then incubated at $28^{\circ} \mathrm{C}$ for five days. Inoculum of $M o T$ was prepared by suspending colonies from fresh five days culture plate into the test tube containing sterilized physiological saline solution $(0.9 \% \mathrm{NaCl} w / \mathrm{v})$. The turbidity of $M o T$ was adjusted either by the addition of more colonies or saline water to 0.5 McFarland standard corresponding to $1.5 \times 10^{8} \mathrm{CFU} / \mathrm{mL}$ [19]. This seed culture was used for activity screening of medicinal plant extracts. All the microbial culture works were done under aseptic condition.

\subsection{Activity Assay against MoT}

To prepare the activity assay plate, $\mathrm{PDA}$ medium was sterilized at $121^{\circ} \mathrm{C}$ for 20 min by autoclave machine. The medium was poured on the sterilized Petri dish $(120 \mathrm{~mm})$ and left to solidify in laminar airflow cabinet. The antibacterial activity test of the plant extracts was done by using a disc diffusion method [20]. $50 \mu \mathrm{L}$ standardized suspension of $M o T$ strains of $1.5 \times 10^{8} \mathrm{CFU} / \mathrm{mL}$ was diffused on the potato dextrose agar (PDA) medium with sterilized swabs. Each extract was diluted with an appropriate combination of ethyl acetate and methanol in such way that $10 \mu \mathrm{L}$ contains $5 \mathrm{mg}$ extract. $10 \mu \mathrm{L}$ of each extract was soaked in sterile filter paper discs (6 mm diameter), fully dried under laminar air flow cabinet and then placed on test pathogen swabbed agar and incubated at $28^{\circ} \mathrm{C}$ for 10 days. After incubation, the diameter of zone of inhibition for each extract was measured in millimeter using a measuring scale. Iprodione $(5 \mathrm{mg} /$ disk $)$ and one sterile empty paper disk $(6 \mathrm{~mm})$ were used as positive (standard) and negative controls in this experiment, respectively. Mean value \pm standard deviation of 3 replications were used in Table 2.

\section{Results and Discussion}

In vitro antifungal activity of 12 medicinal plants was evaluated against notorious wheat blast causing pathogen, MoT. The zones of inhibition (mm) exhibited by plant extracts are listed in Table 2 . Among the studied plant extracts, the remarkable inhibitory activity $\{(29.6 \pm 01.5) \mathrm{mm},(25.1 \pm 01.0) \mathrm{mm}$ and $(20.0$ $\pm 02.0) \mathrm{mm}$ zone of inhibition $\}$ showed $(5 \mathrm{mg} /$ disk) obtained from Artemisia indica (Nagdona), Persicaria orientalis (Biskatali) and Clerodendrum indicum (Bamonhati), respectively. Other extracts (1 and 8) showed zone of inhibition ranged between 8-12 mm (Table 2 and Figure 1). It is noted that extracts 2, 3, 4, 5, 7, 10 and 12 did not show any activity against tested pathogen. The same extracts were tested for their activity against another pathogen Penicillium sp. (common endophytic fungus of cereal plants like wheat and soybean). Unfortunately, all extracts did not show any activity against tested pathogen (Figure 2) at applied concentrations ( $5 \mathrm{mg} / \mathrm{disc})$, whereas the standards showed activity (zone of inhibition $20.0 \pm 01.0 \mathrm{~mm}$ ) against the said pathogen.

Presently, wheat production in Bangladesh is under threat due to outbreak of devastating blast disease caused by $M o T$ [21]. Although some synthetic fungicides 
are being used for controlling wheat blast but heavily and frequent use of these fungicides imposing enormous threat to human and plant health as well as beneficial microorganisms, and ultimately leading to develop resistance by the pathogens.

Application of natural pesticides is one of the sustainable approaches to manage wheat blast especially originated from plant sources. Plant extracts have been well-known for their medicinal and antimicrobial properties since the history of

Table 2. Yield of extracts of different medicinal plants and their activity against $M o T$ (Magnaporthe Oryzae Triticum).

\begin{tabular}{ccccc}
\hline SL & Vernacular Name & Scientific Name & $\begin{array}{r}\text { Yield } \\
\text { (in g) }\end{array}$ & $\begin{array}{c}\text { Zone of inhibition } \\
\text { (in mm) against MoT }\end{array}$ \\
\hline 1 & Sorpogandha & Rauvolfia serpentia & 1.72 & $08.6 \pm 01.1$ \\
2 & Joyunti & Sesbania sesban & 1.52 & - \\
3 & Polash & Butea monosperma & 0.96 & - \\
4 & Sugandhibala & Pandanus amaryllifolius & 0.48 & - \\
5 & Vhuikumra & Ipomoea mauritiana & 0.72 & - \\
6 & Biskatali & Persicaria orientalis & 1.96 & $25 \pm 01.0$ \\
7 & Joipal & Croton tiglium & 1.40 & - \\
8 & Bamonhati & Clerodendrum indicum & 1.04 & $20 \pm 02.0$ \\
9 & Punarnava & Boerhaavia repens & 1.28 & $11.6 \pm 01.5$ \\
10 & Aunantamul & Hemidesmus indicus & 1.01 & - \\
11 & Nagdona & Artemisia indica & 1.08 & $29.6 \pm 01.5$ \\
12 & Currypata & Melia sempervirens & 1.04 & - \\
13 & Iprodione (+ve control) & - & - & $15 \pm 01.0$ \\
14 & Blank disk (-ve control) & - & - & $0.0 \pm 0.0$ \\
\hline
\end{tabular}

“-” indicate not active in tested concentration. Mean value \pm standard deviation of 3 replications were used in Table.

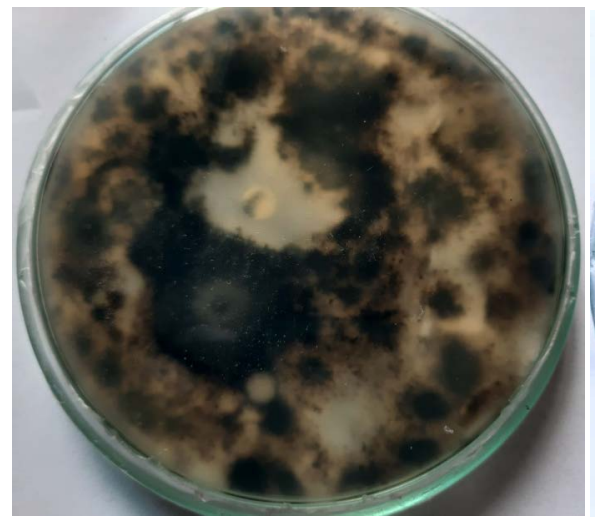

Control

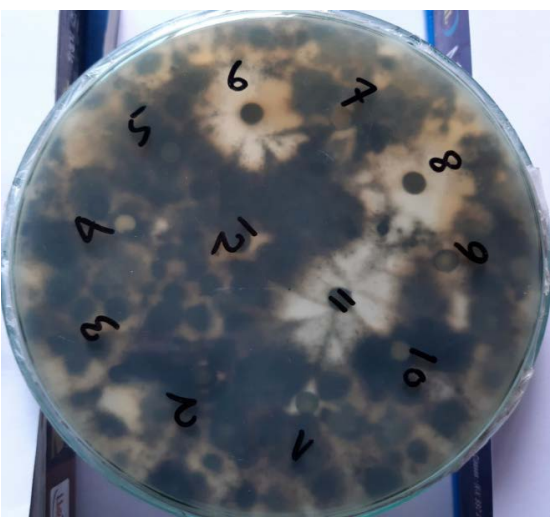

Extracts

Figure 1. Antifungal activity of control and 12 (serial numbers 1 to 12 of Table 2) extracts against notorious wheat causal agent, MoT (Magnaporthe Oryzae Triticum) pathotype. 


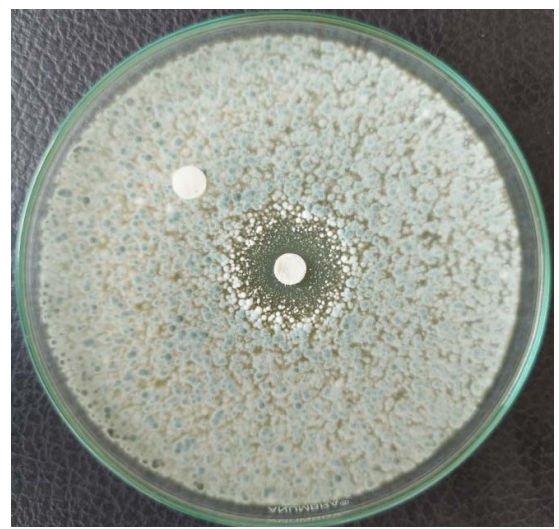

Control

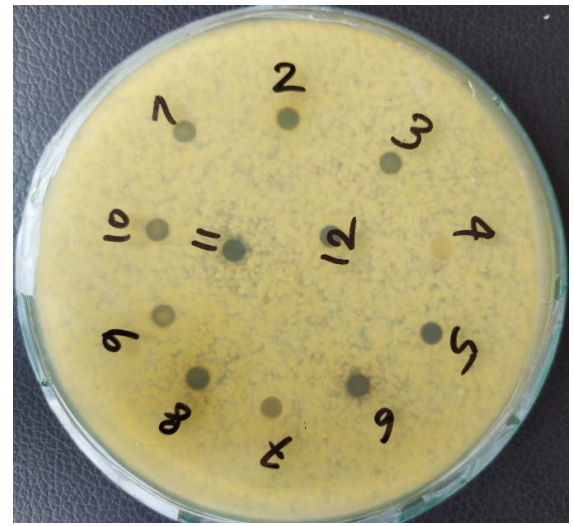

Extracts

Figure 2. Antifungal activity of control and 12 (serial numbers 1 to 12 of Table 2) extracts against Penicillium sp. (common endophytic fungus of cereal plants like wheat).

mankind [22]. They offer a greater scope for sustainable agriculture than synthetic chemicals as they are relatively safe, easily biodegradable and eco-friendly. Natural pesticides from plants are cheap, readily available and cost-effective for poor farmers in developing countries where synthetic fungicides are scarce and expensive [23].

Fungi are the main casual agents of plant diseases which cause a considerable loss of crop yield across the world. Some scientists had been reported that in an in vitro experiment, garlic clove extract (1:10 dilution) completely inhibited mycelia growth (up to 93.33\%) of MoT and minimized disease incidence and severity with promotion of yield parameters [24]. The plant extracts obtained from processed coffee (C. arabica) exhibited $81.12 \%$ and $89.40 \%$ inhibitory effect at concentrations of $10 \%$ and $25 \%(\mathrm{w} / \mathrm{v})$, respectively against Pyricularia grisea-the causal agent of rice blast disease with no phytotoxic to rice seedlings in applied concentration [25].

The methanol extract obtained from stems of a tree, Catalpa ovata, exhibited potent in vivo antifungal activity against the most severe rice blast disease causal agent, Magnaporthe grisea [26]. In an in vivo experiment with methanol extracts of invasive plants, Amorpha fruticosa and Phytolacca americana, showed potent antifungal activity at $3000 \mathrm{ppm}$ against severe crop fungal diseases viz., rice blast, tomato gray mold, pepper anthracnose and tomato late blight [27]. Methanol extract of Lawsonia inermis leaves exhibited potent antifungal activity against major plant pathogenic fungi [28]. Pythium debaryanum is a fungal species causes diseases many wild and cultivated plants against which methanol extracts of Lawsonia inermis, Mimosa pudica and Phyllanthus niruri revealed marked activity (25 mm, $20 \mathrm{~mm}$ and $20 \mathrm{~mm}$ inhibition zone, respectively) at a concentration of $40 \mathrm{mg} /$ disk [29].

In the present study, when zone of inhibition against MoT is compared in same concentration ( $5 \mathrm{mg} /$ disk) among the most active extract obtained from Artemisia indica (Nagdona), Persicaria orientalis (Bishkatali) and Cleroden- 
drum indicum (Bamonhati), respectively and standard (iprodione), it has been shown that iprodione produced less zone of inhibition $(15 \pm 01.0 \mathrm{~mm})$ than extract of these three plants $\{(29.6 \pm 01.5) \mathrm{mm},(25.1 \pm 01.0) \mathrm{mm}$ and $(20.0 \pm 02.0)$ $\mathrm{mm}$ zone of inhibition, respectively)\}. Note that in case of iprodione, it is a pure compound whereas extract of these plants may contain many compounds out of which 2 - 3 compounds of each may be active. Accordingly, the pure form of these 2 - 3 compounds of plant extract may be more active than standard, iprodione. It may conclude that these plants extract will be a hopeful source for developing natural fungicides against wheat blast pathogen like $M o T$.

There are several approaches in developing plant-derived natural pesticides in a cost-effective way: 1) Traditional extraction of bioactive secondary metabolites by solvents (e.g., water, methanol etc.) under conditions from the field-grown plants that produce the highest levels of the compounds, determination of the dose of the bioactive extracts against target pests through lab and field level in vivo activity test; 2) Bioassay guided isolation and characterization of the plant-derived active secondary metabolites and subsequently their production through synthesis from inexpensive precursors or through fermentation by gene transfer to microorganisms and fixing dose through lab and field level experiments; 3) Enhancing biosynthesis of the target plant-derived bioactive compounds through inexpensively synthesized metabolic precursors; 4) Using plant growth regulators, elicitors, and metabolic blockers with a view to increase production of plant-derived target pesticides and so on. Therefore, active compounds of Artemisia indica (Nagdona), Persicaria orientalis (Bishkatali) and Clerodendrum indicum (Bamonhati) against wheat blast may be subjected to developing eco-friendly and cost-effective natural fungicides for sustainable agricultural practices following any one of the above appropriate approach.

\section{Conclusion}

The current findings suggest that extract obtained from leaves and stems of $A r$ temisia indica (Nagdona), Persicaria orientalis (Bishkatali) and Clerodendrum indicum (Bamonhati) possess significant antifungal properties $\{(29.6 \pm 01.5)$ $\mathrm{mm},(25.1 \pm 01.0) \mathrm{mm}$ and $(20.0 \pm 02.0) \mathrm{mm}$ zone of inhibition, respectively $)\}$ against MoT (Magnaporthe Oryzae Triticum) pathotype. The methanol extracts obtained from these medicinal plants are affordable, safe and eco-friendly. However, the further research is required to identify and characterize the active antifungal compounds in the extract and their role in wheat blast disease control in order to develop natural and eco-friendly fungicides.

\section{Acknowledgements}

I express my sincere gratitude to the authority of Bangladesh Open University for funding this research. I would like to thank Dr. Md. Israil Hossain, Director General, Bangladesh Wheat and Maize Research Institute (BWMRI), Nashipur, Dinajpur for providing MoT (Magnaporthe Oryzae Triticum) pathotype. I also 
extend my deep gratitude to Bangladesh Rice Research Institute (BRRI), Gazipur, Bangladesh for providing Penicillium sp. pathotype.

\section{Conflicts of Interest}

The author declares no conflicts of interest regarding the publication of this paper.

\section{References}

[1] Geraldin, M.W.L., James W.M. and Ernest, R.M. (2020) Phytochemical Activity and Role of Botanical Pesticides in Pest Management for Sustainable Agricultural Crop Production. Scientific African, 7, e00239. https://doi.org/10.1016/j.sciaf.2019.e00239

[2] Callaway, E. (2016) Devastating Wheat Fungus Appears in Asia for First Time. Nature 532, 421-422. https://doi.org/10.1038/532421a

[3] Savary, S., Ficke, A., Jean-Noel, A. and Hollier, C. (2012) Crop Losses Due to Diseases and Their Implications for Global Food Production Losses and Food Security. Food Security, 4, 519-537. https://doi.org/10.1007/s12571-012-0200-5

[4] Islam, M.T., Kim, K.H. and Choi, J. (2019) Wheat Blast in Bangladesh: The Current Situation and Future Impacts. The Plant Pathology Journal, 35, 1-10. https://doi.org/10.5423/PPJ.RW.08.2018.0168

[5] Fisher, M.C., Henk, D.A., Briggs, C.J., Brownstein, J.S., Madoff, L.C., Mc. Craw, S.L. and Gurr, S.J. (2012) Emerging Fungal Threats to Animal, Plant and Ecosystem Health. Nature, 484, 186-194. https://doi.org/10.1038/nature10947

[6] Pennisi, E. (2010) Armed and Dangerous. Science, 327, 804-805. https://doi.org/10.1126/science.327.5967.804

[7] Igarashi, S., Utiamada, C.M., Igarashi, L.C., Kazuma, A.H. and Lopes, R.S. (1986) Pyricularia em trigo. 1. Ocorrencia de Pyricularia sp. no estado do Parana. Fitopatologia Brasileira, 11, 351-352. (in Português)

[8] Inoue, Y., Vy, T.T.P., Yoshida, K., Asano, H., Mitsuoka, C., Asuke, S., et al. (2017) Evolution of the Wheat Blast Fungus through Functional Losses in a Host Specificity Determinant. Science, 357, 80-83. https://doi.org/10.1126/science.aam9654

[9] Cruz, C.D. and Valent, B. (2017) Wheat Blast Disease: Danger on the Move. Tropical Plant Pathology, 42, 210-222. https://doi.org/10.1007/s40858-017-0159-Z

[10] Mahmood, I., Imadi, S.R., Shazadi, K., Gul, A. and Hakeem, K.R. (2016) Effects of Pesticides on Environment. In: Hakeem, K., Akhtar, M. and Abdullah, S., Eds., Plant, Soil and Microbes, Springer, Cham, 253-269.

https://doi.org/10.1007/978-3-319-27455-3_13

[11] Islam, M.T., Croll, D., Gladieux, P., Soanes, D.M., Persoons, A., Bhattacharjee, P., et al. (2016) Emergence of Wheat Blast in Bangladesh Was Caused by a South American Lineage of Magnaporthe oryzae. BMC Biology, 14, Article No. 84.

https://doi.org/10.1186/s12915-016-0309-7

[12] Malaker, P.K., Barma, N.C.D., Tiwari, T.P., Collis, W.J., Duveiller, E., Singh, P.K., et al. (2016) First Report of Wheat Blast Caused by Magnaporthe oryzae Pathotype triticum in Bangladesh. Plant Disease, 100, 2330-2330. https://doi.org/10.1094/PDIS-05-16-0666-PDN

[13] Raja, N. (2014) Botanicals: Sources for Eco-Friendly Biopesticides. Journal of Biofertilizers \& Biopesticides, 5, Article No. e122. https://doi.org/10.4172/2155-6202.1000e122 
[14] Nikkhah, M., Hashemi, M., Mohammad, B., Habibi, N. and Farhoosh, R. (2017) Synergistic Effects of Some Essential Oils against Fungal Spoilage on Pear Fruit. International Journal of Food Microbiology, 257, 285-294. https://doi.org/10.1016/j.ijfoodmicro.2017.06.021

[15] Karaca, G., Bilginturan, M. and Olgunsoy, P. (2017) Effects of Some Plant Essential Oils against Fungi on Wheat Seeds. Indian Journal of Pharmaceutical Education and Research, 3, s385-s388. https://doi.org/10.5530/ijper.51.3s.53

[16] Mishra. R.K., Bohra, A., Kamaal, N., Kumar, K., Gandhi, K., Sujayan, G.K. and Mishra, M. (2018) Utilization of Biopesticides as Sustainable Solutions for Management of Pests in Legume Crops: Achievements and Prospects. Egyptian Journal of Biological Pest Control, 28, Article No. 3.

https://doi.org/10.1186/s41938-017-0004-1

[17] Martinez, A.J. (2012) Natural Fungicides Obtained from Plants. In: Dhanasekaran, D., Ed., Fungicides for Plant and Animal Diseases, IntechOpen.

http://www.intechopen.com/books/fungicides-for-plant-and-animal-diseases/natur al-fungicides-obtained-from-plants

[18] Yoon, M.Y., Cha, B. and Kim, J.C. (2013) Recent Trends in Studies on Botanical Fungicides in Agriculture. The Plant Pathology Journal, 29, 1-9.

https://doi.org/10.5423/PPJ.RW.05.2012.0072

[19] Kiehlbauch, J.A., Hannett, G.E., Salfinger, M., Archinal, W., Monserrat, C. and Carlyn, C. (2000) Use of the National Committee for Clinical Laboratory Standards Guidelines for Disk Diffusion Susceptibility Testing in New York State Laboratories. Journal of Clinical Microbiology, 38, 3341-3348. https://doi.org/10.1128/JCM.38.9.3341-3348.2000

[20] Jorgensen, J.H. and Turnidge, J.D. (2015) Susceptibility Test Methods: Dilution and Disk Diffusion Methods. In: Jorgensen, J.H., Carroll, K.C., Funke, G., Pfaller, M.A., Landry, M.L., Richter, S.S., Warnock, D.W., Richter, S.S. and Patel, J.B., Eds., Manual of Clinical Microbiology, 11th Edition, American Society of Microbiology, 1253-1273. https://doi.org/10.1128/9781555817381.ch71

[21] Peng, J.L., Zhou, Y.L. and He, Z.H. (2011) Global Warning against the Spread of Wheat Blast. Journal of Triticeae Crops, 31, 989-993.

[22] Jabeen, R. (2006) Evaluation of Botanicals against Xanthomonas oryzae pv. oryzae Using Bacterial Leaf Blight Disease of Rice and Characterization of Bioactive Compounds. MSc. Dissertation, Quaid-i-Azam University, Islamabad.

[23] Mossini, S.A.G., Oliveira, K.P. and Kemmelmeier, C. (2004) Inhibition of Patulin Production by Penicillium expansum Cultured with Neem (Azadirachta indica) Leaf Extracts. Journal of Basic Microbiology, 44, 106-113.

https://doi.org/10.1002/jobm.200310332

[24] Zohura, F.T., Kashem, M.A., Hasan, M.A.I. and Hossain, M.A. (2018) Effects of Plant Extracts on Controlling Wheat Blast Disease Caused by Magnaporthe oryzae Pathotype Triticum in Bangladesh. Fundamental and Applied Agriculture, 3, 422-433. https://doi.org/10.5455/faa.293640

[25] Hubert, J., Mabagala, R.B. and Mamiro, D.P. (2015) Efficacy of Selected Plant Extracts against Pyricularia grisea, Causal Agent of Rice Blast Disease. American Journal of Plant Sciences, 6, 602-611. https://doi.org/10.4236/ajps.2015.65065

[26] Cho, J.Y., Kim, H.Y., Choi, G.J., Jang, K.S., Lim, H.K., Lim, C.H., Cho, K.Y. and Kim, J.C. (2006) Dehydro- $\alpha$-Lapachone Isolated from Catalpa ovatastems. Activity against Plant Pathogenic Fungi. Pest Management Science, 62, 414-418. https://doi.org/10.1002/ps.1180 
[27] Bajpai, V.K., Baek, K.-H., Kim, E.S., Han, J.E., Kwak, M., Oh, K., Kim, J.-C., Kim, S. and Choi, G.J. (2012) In Vivo Antifungal Activities of the Methanol Extracts of Invasive Plant Species against Plant Pathogenic Fungi. The Plant Pathology Journal, 28, 317-321. https://doi.org/10.5423/PPJ.NT.04.2012.0056

[28] Khan, Z.S. and Nasreen, S. (2010) Phytochemical Analysis, Antifungal Activity and Mode of Action of Methanol Extracts from Plants against Pathogens. Jounal of Agricultural Technology, 6, 793-805.

[29] Ambikapathy, V., Gomathi, S. and Panneerselvam, A. (2011) Effect of Antifungal Activity of Some Medicinal Plants against Pythium debaryanum (Hesse). Asian Journal of Plant Sciences, 1, 131-134. 